\title{
Dysregulated human Tyrosyl-DNA phosphodiesterase I acts as cellular toxin
}

\author{
Selma M. Cuya ${ }^{1}$, Evan Q. Comeaux ${ }^{1,2}$, Keith Wanzeck ${ }^{1,3}$, Karina J. Yoon ${ }^{1}$, Robert \\ C.A.M. van Waardenburg ${ }^{1}$ \\ ${ }^{1}$ Department of Pharmacology and Toxicology, University of Alabama at Birmingham, Birmingham, AL 35294-0019, USA \\ ${ }^{2}$ Department of Pathology, St. Jude Children's Research Hospital, Memphis, TN 38105-3678, USA \\ ${ }^{3}$ Department of Medicine, Division of Clinical Immunology \& Rheumatology, University of Alabama at Birmingham, \\ Birmingham, AL 35294-0001, USA
}

Correspondence to: Robert C.A.M. van Waardenburg, email: rvanwaar@uab.edu

Keywords: TDPI, DNA-adducts, biochemistry, DNA topoisomerases, DNA repair

Received: July 16, 2016

Accepted: November 09, 2016

Published: November 23, 2016

\section{ABSTRACT}

Tyrosyl-DNA phosphodiesterase I (TDP1) hydrolyzes the drug-stabilized 3'phospho-tyrosyl bond formed between DNA topoisomerase I (TOPO1) and DNA. TDP1-mediated hydrolysis uses a nucleophilic histidine (His ${ }^{\text {nuc }}$ ) and a general acid/ base histidine (Hisgab). A Tdp1Hisgab to Arg mutant identified in patients with the autosomal recessive neurodegenerative disease SCAN1 causes stabilization of the TDP1-DNA intermediate. Based on our previously reported His ${ }^{\text {ab-substitutions }}$ inducing yeast toxicity (Gajewski et al. J. Mol. Biol. 415, 741-758, 2012), we propose that converting TDP1 into a cellular poison by stabilizing the covalent enzyme-DNA intermediate is a novel therapeutic strategy for cancer treatment. Here, we analyzed the toxic effects of two TDP1 catalytic mutants in HEK293 cells. Expression of human Tdp1HisnucAla and Tdp1Hisgab Asn mutants results in stabilization of the covalent TDP1-DNA intermediate and induces cytotoxicity. Moreover, these mutants display reduced in vitro catalytic activity compared to wild type. Co-treatment of Tdp1 $1^{\text {mutant }}$ with topotecan shows more than additive cytotoxicity. Overall, these results support the hypothesis that stabilization of the TDP1-DNA covalent intermediate is a potential anti-cancer therapeutic strategy.

\section{INTRODUCTION}

Tyrosyl-DNA phosphodiesterase I (TDP1) hydrolyzes 3'phospho-adducts and to a limited extent 5 'phospho-adducts within DNA strand breaks (reviewed in [1]). Tdp1 catalysis is structurally and mechanistically conserved from yeast (y) to human (h), and centers on the formation and resolution of a requisite covalent TDP1-DNA reaction intermediate, also called a TDP1DNA covalent complex (TDP1-cc) (Figure 1). This two-step cycle utilizes spatial and temporal coordinated action of two catalytic histidines [2-8]. During step 1, the nucleophilic histidine (His ${ }^{\text {nuc }}$ : hTDP1His ${ }^{263}$ and yTDP1His ${ }^{182}$ ) attacks the DNA 3'phospho-adduct bond to form a TDP1-cc. In step 2, the second histidine functions as a general acid/base (His ${ }^{\text {gab }}$ hTDP1His ${ }^{493}$ and yTDP1His ${ }^{432}$ ) and activates water to hydrolyze the 3'phospho-hystidyl (TDP1His ${ }^{\text {nuc }}$-DNA) linkage, dissociating TDP1 from the DNA (Figure 1) [2-8].

Besides the DNA repair enzyme TDP1, DNA topoisomerases (TOPOs; TOPO is used instead of the official abbreviation "TOP" to emphasize the difference between the protein names TDP1 and TOP1) that adjust DNA topology form a transient covalent enzyme-DNA reaction intermediate (TOPO-cc) during their catalytic cycle (review in [9-11]). However, this transient covalent enzymeDNA intermediate can potentially result in toxic DNA lesions. This paradigm is extensively exploited by cancerchemotherapeutics that induce toxicity via stabilization of the enzyme-DNA intermediate, e.g. etoposide for TOPO2 and camptothecin (CPT) for TOPO1, including FDAapproved CPT analogs topotecan and irinotecan [12, 13].

Most enzymes that form a covalent-phosphoryl reaction intermediate with a DNA-end are potential 
substrates for TDP1. Hence, TDP1 is able to hydrolyze 3'phospho-tyrosyl (TOPO1-DNA), 3'phospho-hystidyl (TDP1-DNA), and 5'phospho-tyrosyl (TOPO2-DNA) linkages [3, 4, 11, 13-21]. Moreover, TDP1 is also able to hydrolyze smaller substrates predominantly from the 3 '-end of the DNA but also 5' oriented adducts including damaged nucleotides, such as 3'phospho-glycolates or 5'- and 3'-abasic sites generated by oxidative damage, $\gamma$-irradiation and/or chain terminating nucleosides, e.g. cytarabine and acyclovir [4, 18, 22-27]. Thus, TDP1 is a versatile DNA repair enzyme involved in the removal of DNA-adducts generated by a wide variety of chemotherapeutics and endogenously generated toxins.

Stabilization of enzyme-DNA intermediates can also be achieved via the introduction of mutations. For example, there is a naturally occurring Tdp1 His ${ }^{\text {gab }} \mathrm{Arg}$ $\left(\mathrm{hTdp} 1 \mathrm{H}^{493} \mathrm{R}\right)$ mutation identified in patients with the neurodegenerative disease spinocerebellar ataxia with axonal neuropathy (SCAN1) [28]. This point mutation enhances the stability of the covalent $\mathrm{Tdp} 1^{\mathrm{H} 493 \mathrm{R}}$-cc due to delayed hydrolysis of the 3'phospho-histidyl bond [3, 29]. Moreover, the His ${ }^{\text {gab }}$ Arg mutant enzyme characteristics are conserved from human to yeast. Some of those characteristics include increased stability of the TDP1-DNA complex that coincides with a reduced catalytic activity in vitro and increased cell sensitivity to DNA damaging agents, such as CPT, bleomycin, $\mathrm{H}_{2} \mathrm{O}_{2}$, $\gamma$-irradiation, and chain-terminating nucleoside analogs [3, $4,22,30,31]$. Additionally, we have identified alternative substitutions of yTDP1His ${ }^{\text {gab }}$, including yTdp $1 \mathrm{H}^{432} \mathrm{~N}$, that induce more severe cellular toxicity than the yeast SCAN1-mutant analog (yTdp1 $\left.\mathrm{H}^{432} \mathrm{R}\right)$ [3, 4]. Moreover, the $y T d p 1 H^{432} \mathrm{~N}$ mutant formed stable TDP1-DNA intermediates in yeast $[3,4]$. These observations suggest that TDP1-DNA intermediate stabilization by catalytic dysregulation converts yTDP1 into a cellular poison, exposing a potential novel anti-cancer therapeutic strategy.

\section{RESULTS}

\section{Expression of hTDP1 mutants in yeast induces hTOPO1-dependent toxicity}

To examine if the molecular basis of the TDP1induced toxicity of yTDP1 catalytic mutants $[3,4,32]$ is a conserved property of the TDP1 family, we generated the analogous human $\mathrm{His}^{\text {nuc }} \mathrm{Ala}\left(\mathrm{H}^{263} \mathrm{~A}\right)$ and $\mathrm{His}^{\mathrm{gab}} \mathrm{Arg} /$ Asn $\left(\mathrm{H}^{493} \mathrm{R} / \mathrm{N}\right)$ substitutions. Mutant hTDP1 alleles were expressed from plasmid-borne galactose-inducible (GAL1) promoter constructs. To facilitate species-specific interactions, hTOPO1 was also expressed from the GAL1promoter but borne on a different plasmid. Co-expression of the hTDP1 mutants with hTOPO1 in a TOP1,TDP1 deleted (top $1 \Delta, t d p 1 \Delta$ ) yeast strain [32] induced a TOPO1dependent cellular toxicity (Figure 2A). Expression of the $\mathrm{hTdp} 1 \mathrm{H}^{493} \mathrm{R}$ mutant had marginal effects on yeast cell viability, similar to wild type hTDP1, while hTdp $1 \mathrm{H}^{493} \mathrm{~N}$ and $\mathrm{hTdp} 1 \mathrm{H}^{263} \mathrm{~A}$ expression induced toxicity (Figure $2 \mathrm{~A}$ ). The expression level of the catalytic mutants was similar to wild type, suggesting that the phenotypes are due to alterations in catalytic function rather than a difference in expression (Figure 2B) or expression levels of yeast and human TOPO1 (shown in [3]). The observed phenotypes for these hTDP1 mutants are not as robust as the analogous yeast mutants, which is likely due to the expression of human enzymes in yeast.
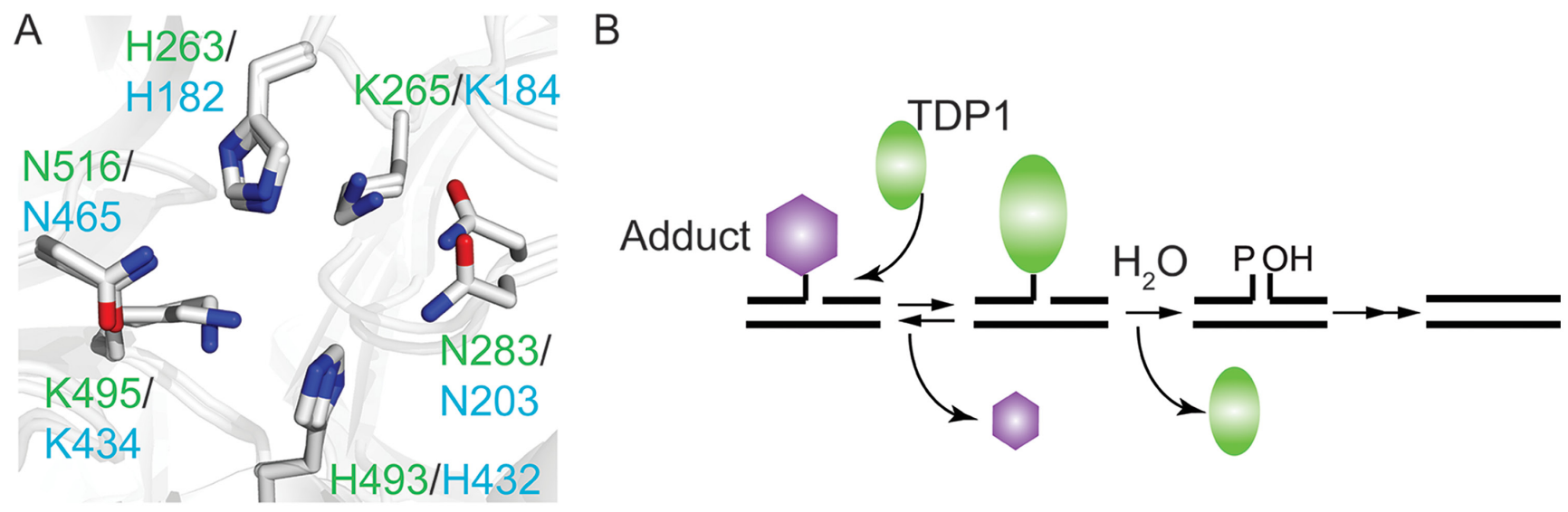

Figure 1: The TDP1 catalytic mechanism is conserved from yeast to human. A. Overlay of yeast and human crystal protein structure showing the catalytic HxK-motif; labeled in green are human TDP1 residue numbering (PDB \# 1NOP [2]) and in cyan the yeast TDP1 residue numbering (PDB\# 1Q32 [4]). His263 in hTDP1 and His182 of yTDP1 represent the nucleophilic Histidine (His ${ }^{\text {nuc }}$ ), while His493 of hTDP1 and His432 in yTDP1 represent the general acid/base Histidine (His $\left.{ }^{\text {gab }}\right)$. B. TDP1 two-step catalytic mechanism. Step 1 (Formation): TDP1 resolves the DNA-adduct via nucleophilic attack of the His ${ }^{\text {nuc }}$ that releases the adduct and generates a TDP1-DNA covalent complex via the 3'phospho-amide bond. Step 2 (Dissociation): His sab activates a water molecule that hydrolyze the TDP1-DNA linkage, dissociating TDP1 from the DNA, leaving behind a single-strand nick, which requires further processing by polynucleotide kinasephosphatase prior to DNA ligation. 


\section{TDP1 catalytic mutants reduce colony formation of HEK293 cells}

The phenotypes induced by the hTdp1 mutants in our yeast model imply a conserved mechanism underlying the substrate (TOPO1)-dependent toxicity caused by dysregulated TDP1 enzymes [3, 4, 32]. To determine if these TDP1 mutant enzymes induce toxicity in human cells, we stably transfected HEK293T-REx (HEK293Tetracycline-Regulated Expression) cells with control (no hTDP1), wild-type $\mathrm{h} T D P 1, \mathrm{~h} T d p 1 H^{493} N$, and $\mathrm{h} T d p 1 H^{263} A$ expression vectors. The HEK293T-REx cells contain the Tet-on expression system in which doxycycline (Dox) treatment induces ectopic $\mathrm{h} T D P 1, \mathrm{~h} T d p 1 H^{493} N$, and $\mathrm{hTdp} 1 \mathrm{H}^{263} \mathrm{~A}$ expression from a modified $\mathrm{CMVTetO}_{2}$ promoter. Moreover, these immortalized human cells express endogenous TDP1 and TOPO1, allowing for the assessment of the toxic effects of TDP1 mutants with endogenous TDP1 substrate (e.g. TOPO1-DNA) levels in ABSENCE of additionally induced genotoxic stress. It is noteworthy that in our yeast model these conditions do not result in a toxic phenotype $[3,4,32]$.

To evaluate the cytotoxicity induced by the TDP1 mutants we used an anchorage-dependent colony formation assay. Cell viability of Dox-induced cells expressing the ectopic hTDP1 allele was determined and plotted relative to the not-induced isogenic cells (no TDP1 expression=100\%). Expression of wild-type hTDP1 induced a reduction in cell viability similar to Dox treatment alone (vector control). Conversely, expression of each mutant TDPI allele induced a significant reduction in cell viability compared to both vector and hTDP1 expressing cells (Figure 3A). Thus, similar to yTDP1, hTDP1 can be converted into a cellular toxin by mutation of either catalytic histidine.
The levels of ectopic expressed protein are $>100$ fold over endogenous TDP1 levels, which is similar as reported by Barthelmes et al. [14]. Analysis of hTDP1 protein levels demonstrated a consistent reduction of the hTdp $1 \mathrm{H}^{493} \mathrm{~N}$ mutant compared to wild type (Figure 3B). This might indicate that the mutant enzyme is trapped on the DNA.

\section{TDP1 mutants accumulate covalent enzyme- DNA intermediates in cell}

To determine if the toxicity induced by hTdp $1 \mathrm{H}^{493} \mathrm{~N}$ and $h T d p 1 H^{263} \mathrm{~A}$ is due to accumulation of covalent enzyme-DNA complexes, we took a two-pronged approach. First, we performed a band-depletion assay in order to observe depletion of the soluble fraction of TDP1 and recovery of the depleted DNA-bound TDP1 fraction via nuclease treatment of the lysate. Immunoblot analysis of cell lysates revealed a significant depletion of hTdp $1 \mathrm{H}^{493} \mathrm{~N}$ protein levels (even when loaded with twice the amount of cell extract as shown in Figure 4A left panel), suggesting TDP1 is bound to DNA. Indeed, mutant hTDP1 protein levels were recovered upon nuclease treatment (Figure 4A right panel). This is similar to the depletion and recovery of $y T d p 1 \mathrm{H}^{432} \mathrm{~N}$ observed previously [4]. Second, we assayed the accumulation of TDP1 protein bound to the genomic DNA by analyzing the cellular distribution of the TDP1 mutants. Equal amounts of cells were harvested and fractionated into the cytosolic/ mitochondrial and nuclear fractions. Subsequently, the nuclear fraction was separated into nucleoplasm and genomic DNA to detect TDP1 protein. The TDP1 protein levels in the cytosolic/mitochondrial fraction (Figure 4B) correlated with the band-depletion results (Figure 4A left panel). Analysis of the nucleoplasm and the shredded
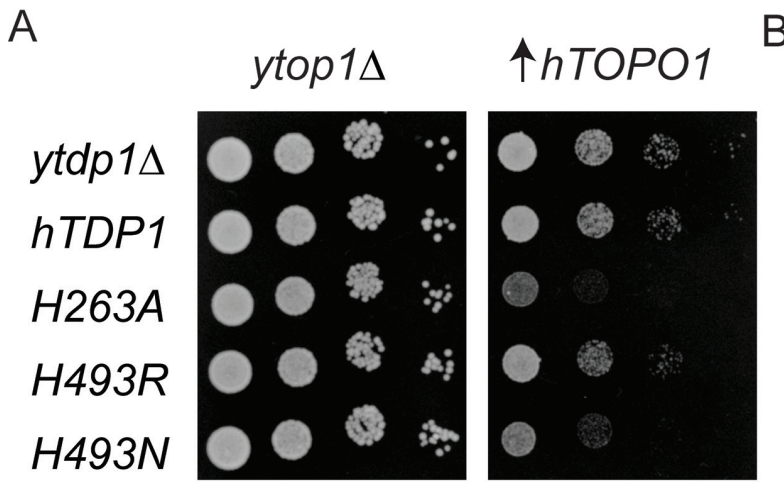

B

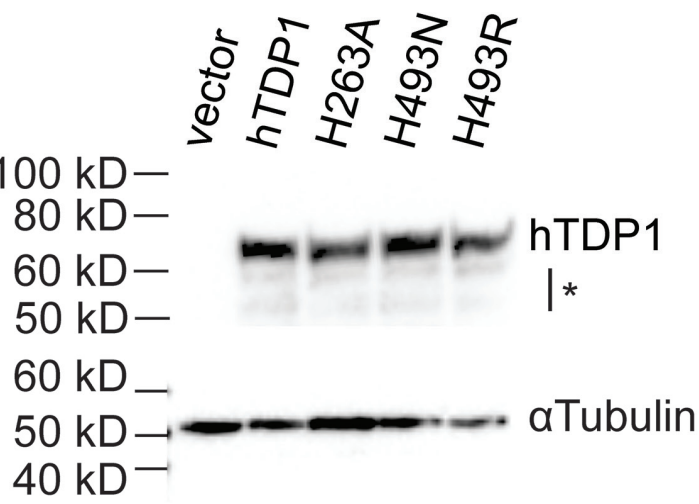

Figure 2: hTDP1 catalytic mutants induce hTOPO1-dependent toxicity. A. top $1 \Delta, t d p 1 \Delta$ cells were co-transformed with vector control (ytop1 $\Delta$ ) or YCpGAL1-hTOP1·U ( $\uparrow$ hTOPO1) and control vector (ytdp1 $\triangle$ ) or the indicated YCpGAL1-hTDP1·L plasmid. Exponentially growing cultures were diluted to an $\mathrm{OD}_{595}$ of 0.3 and ten-fold serially diluted and spotted onto selective galactose plates. Plates were incubated at $30^{\circ} \mathrm{C}$ for 4 days. B. Total cell extracts from galactose induced top $1 \Delta, t d p 1 \Delta$ cells co-transformed with vector control (ytop $1 \triangle$ ) and the indicated YCpGAL1-hTDP1 $\mathrm{L}$ or its control vector (vector) used in (A) were resolved on $12 \%$ SDS-PAGE and stained with anti-human TDP1 and with anti- $\alpha$ Tubulin. *: partly truncated hTDP1 proteins. Blot was cropped and exposure levels were not edited. 
genomic DNA fractions showed that all ectopic expressed proteins are present in the nucleus, however only the hTdp $1 \mathrm{H}^{493} \mathrm{~N}$ and $\mathrm{hTdp} 1 \mathrm{H}^{263} \mathrm{~A}$ proteins are observed in the genomic DNA fraction (Figure 4C). Anti-histone 3 (H3) blotting showed that the genomic DNA fraction was not contaminated with free, unbound proteins of the nucleoplasm (Figure 4C). This supports that the observed Tdp1-mutant depletion is due to increased levels of covalent Tdp $1^{\text {mutant }}$-DNA intermediates.

\section{Tdp1 catalytic mutants display reduced activity} in vitro

To assess the catalytic activity of the hTDP1 enzymes and possible in vitro detection of covalent reaction intermediates, full-length N-terminal FLAGtagged hTDP1 proteins were expressed in a proteasedeficient yeast strain to ensure affinity purified full-length hTDP1 proteins as described in Comeaux et al. [32].

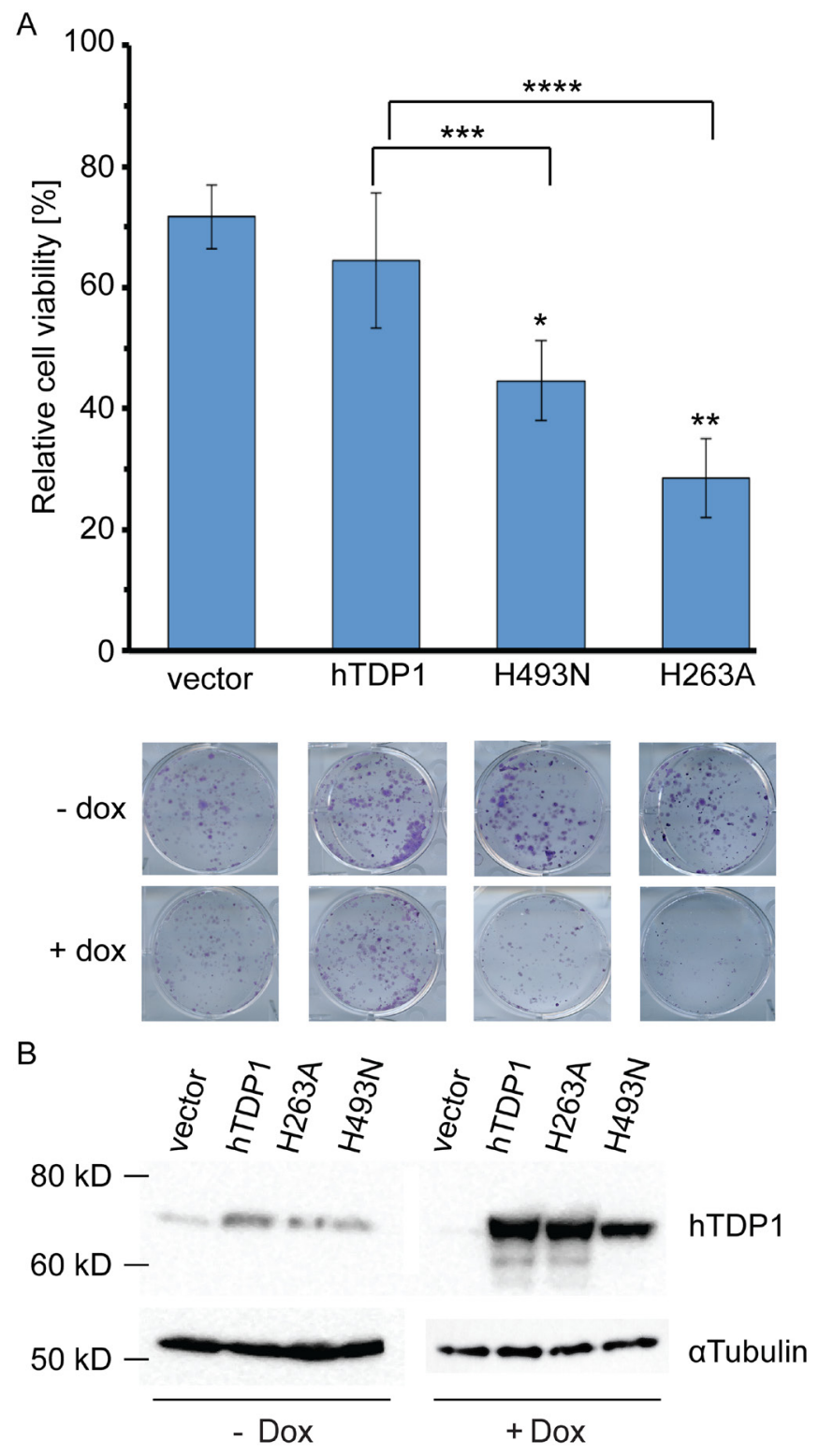

Figure 3: hTDP1H ${ }^{263} \mathrm{~A}$ and $h \mathrm{TDP} 1 \mathrm{H}^{493} \mathrm{~N}$ mutants induce toxicity in human cells in absence of genotoxic stress. A. Stably transfected HEK293 cell lines of hTDP1 with and without Doxycycline (Dox) were incubated at $37^{\circ} \mathrm{C} / 5 \% \mathrm{CO}$ for 10 days and stained with crystal violet. Colonies were quantified using LI-COR Odyssey Infrared Imager at a fluorescence of $700 \mathrm{~nm}$. Relative cell viability was determined for each cell line induced with Dox relative to its isogenic cells without Dox. Results shown of $n=4$. A representative photo is shown taken just before quantification of one well of each cell line/condition. Statistics determined by an unpaired student t-test: Vector-hTDP1: no significance. Vector-mutant: ${ }^{*} \mathrm{p}>0.0007 ; * * \mathrm{p}>0.0002$. hTDP1-mutant: ${ }^{* * *} \mathrm{p}>0.031 ; * * * *(\mathrm{p}>0.0087)$. B. Total extracts of 48 hours +/-Dox induction of each stable cell line were resolved on $12 \%$ SDS-PAGE and stained with anti-human TDP1. Blot is subsequently stripped and re-stained with anti- $\alpha$ Tubulin. For the -Dox $2 \mathrm{x}$ more total extract was loaded than for the + Dox total extracts. 
hTDP1 proteins were incubated in reaction mixtures with $\mathrm{a}^{32} \mathrm{P} 5$ '-end labeled single-stranded oligonucleotide with a 3 'phospho-tyrosyl modification as substrate (Figure 5A). Each reaction was split in two samples and analyzed for either $A$ ) conversion of the 3 'phospho-tyrosyl linkage to a 3'phosphoryl product via a denaturing $20 \% / 8 \mathrm{M}$ Urea polyacrylamide gel electrophoresis (PAGE), or $B$ ) formation of covalent TDP1-DNA reaction intermediates by $12 \%$ SDS-PAGE [3]. Relative to wild type hTDP1, where $\sim 0.45 \mathrm{nM}$ was sufficient to convert $40 \%$ of the substrate into a product, hTdp $1 \mathrm{H}^{493} \mathrm{~N}$ exhibited $\sim 150$-fold lower activity. Surprisingly, hTdp $1 \mathrm{H}^{493} \mathrm{R}$ and hTdp $1 \mathrm{H}^{263} \mathrm{~A}$ exhibited a similar reduction in activity of $\sim 64$-fold less (Figure 5B and 5C). Detection of the hTdp $1 \mathrm{H}^{493} \mathrm{~N}$ DNA intermediates in the Urea-PAGE required longer exposure compared to detection the hTdp $1 \mathrm{H}^{493} \mathrm{R}-\mathrm{DNA}$ intermediates (Figure 5B, *cc represents only the top part of hTdp $1 \mathrm{H}^{493} \mathrm{~N}$ gel). SDS-PAGE analysis confirmed that the detected protein-DNA intermediates are indeed Tdp1DNA covalent complexes and showed that hTdp $1 \mathrm{H}^{493} \mathrm{~N}$ DNA levels are low compared to hTdp $1 \mathrm{H}^{493} \mathrm{R}-\mathrm{DNA}$ levels (Figure 5D). However, this is the first time that covalent TDP1-DNA complexes were detected by a Tdp1His ${ }^{\text {gab }}$ mutant enzyme (yeast or human) other than the $\mathrm{His}^{\mathrm{gab}} \mathrm{Arg}$ substitution. The detected $\mathrm{hTdp} 1 \mathrm{H}^{263} \mathrm{~A}$ enzyme activity supports the observed cellular toxicity and the detection of Tdp $1 \mathrm{H}^{263} \mathrm{~A}$-DNA covalent intermediates in cells (Figures $3 \mathrm{~A}$ and $4 \mathrm{C}$, respectively). Moreover, the question remains as to why we detect -reduced- $\mathrm{hTdp} 1 \mathrm{H}^{263} \mathrm{~A}$ catalytic activity in vitro while it was reported to be catalytically inactive $[5,8]$.

\section{hTdp1H ${ }^{263}$ A Topo1-dependent toxicity requires His $^{262}$}

Despite lacking a nucleophilic histidine, the hTdp $1 \mathrm{H}^{263} \mathrm{~A}$ enzyme displayed catalytic activity and was able to form a covalent intermediate with genomic DNA to induce cytotoxicity. This led us to postulate the presence of an alternative nucleophilic residue within the catalytic pocket. Sequence analysis of TDP1 orthologs exposed a highly conserved histidine preceding the His ${ }^{\text {nuc }}$ as a potential candidate that can act as an alternative nucleophile (Figure 6A). To verify that this histidine, His ${ }^{262}$ in hTDP1, is able to function as an alternative nucleophile, we mutated $\mathrm{His}^{262}$ to Ala in wild-type and hTdp $1 \mathrm{H}^{263} \mathrm{~A}$ mutant alleles. We examined these mutants in our top $1 \Delta, t d p 1 \triangle$ yeast strain by co-expression of the hTDP1 allele with hTOPO1 as discussed above (Figure 2A). We observed that introduction of $\mathrm{H}^{262} \mathrm{~A}$ substitution in hTdp $1 \mathrm{H}^{263} \mathrm{~A}$ and hTDP1 resulted in cell viability similar to the wild type hTDP1 protein, while hTdp $1 \mathrm{H}^{263} \mathrm{~A}$ induced cytotoxicity (Figure 6B). This suggests that the catalytic activity of hTdp $1 \mathrm{H}^{263} \mathrm{~A}$ is mediated by $\mathrm{His}^{262}$ functioning as the alternative nucleophile when the His ${ }^{\text {nuc }}$ is substituted by Ala, which is not caused by differential protein expression levels (data not shown).

\section{Topotecan enhances TDP1-induced toxicity}

To study the potential of TDP1 as a therapeutic drug target, we tested the schedule dependency of the combinational treatment of Tdp1 mutant expression with topotecan (TPT; reversibly stabilizes Topo1-cc). We tested two treatment schedules. First: TDP1 protein expression induced for 4 days, and co-treated with TPT for 3 days. Second: TPT treatment for 4 days and TDP1 protein expression induced for 3 days. All stable cell lines showed a similar sensitivity to TPT alone within each schedule (Figure 7A and 7C). Compared to vector control cells, elevated expression of wild-type hTDP1 increased TPT cell sensitivity to sub-nano molar range, while higher TPT concentration induced similar toxicities in both cell lines within each schedule (Figure 7B and 7D; blue and
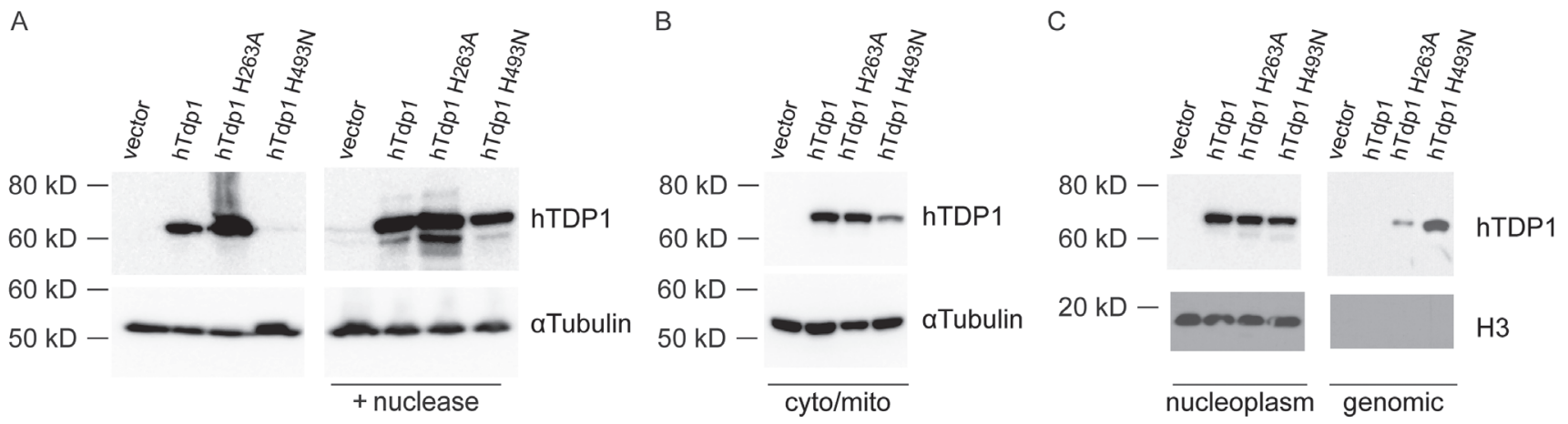

Figure 4: hTDP1 catalytic mutants increase stability of covalent enzyme-genomic DNA intermediates. A. Band-depletion of stably transfected HEK293 cells. Immunoblot of total cell extracts treated with (+ nuclease) or without micrococcal nuclease. Two times more hTDP $1 \mathrm{H}^{493} \mathrm{~N}$ total cell extracts were loaded than other samples to emphasize band-depletion. B-C. Cell fractionation of the stably transfected HEK293 cells used in (A). B. Cytosolic/mitochondrial lysate fraction, and C. Nuclear fraction split in the nucleoplasm and genomic DNA. All samples were resolved via 12\% SDS-PAGE and immunoblotted with anti-hTDP1 and anti- $\alpha$ Tubulin (A-B); anti-hTDP1 and anti-Histone $\mathrm{H} 3(\mathbf{C})$. 
green lines). However, both toxic TDP1 mutant proteins reveal an increased toxicity in combination with TPT over the entire curve in both schedules (Figure 7B and 7D; pink and red lines). TDP1 "poisoning" followed by TPT treatment results in an increase in dynamic range of 4.6- to 35 -fold (Table 1). This suggests that the proposed novel therapeutic strategy of molecular targeting the TDP1-cc can result in synergistic toxicity when combined with TPT, but can also be effective by itself (Figure 7).

Overall TDP1-induced toxicity increased over time. The combination assays exposed a mild increase in TDP1- induced toxicity (without TPT) between 3-day induction (Figure 7D) and 4-day induction (Figure 7B), while a 10day incubation period (colony formation assay; Figure $3 \mathrm{~A}$ ) induced even more toxicity. Both these assays are based on anchorage-dependent cell growth, which leads us to the following thought: "Can poisoning of TDP1 via dysregulation of TDP1-activity using either hTdp $1 \mathrm{H}^{493} \mathrm{~N}$ or hTdp $1 \mathrm{H}^{263} \mathrm{~A}$ mutants also decrease the anchorageindependent colony formation, which is suggested to be a surrogate for the ability to form cancer metastasis [33, 34]?” Indeed, hTdp $1 \mathrm{H}^{263} \mathrm{~A}$ significantly reduced colony
A

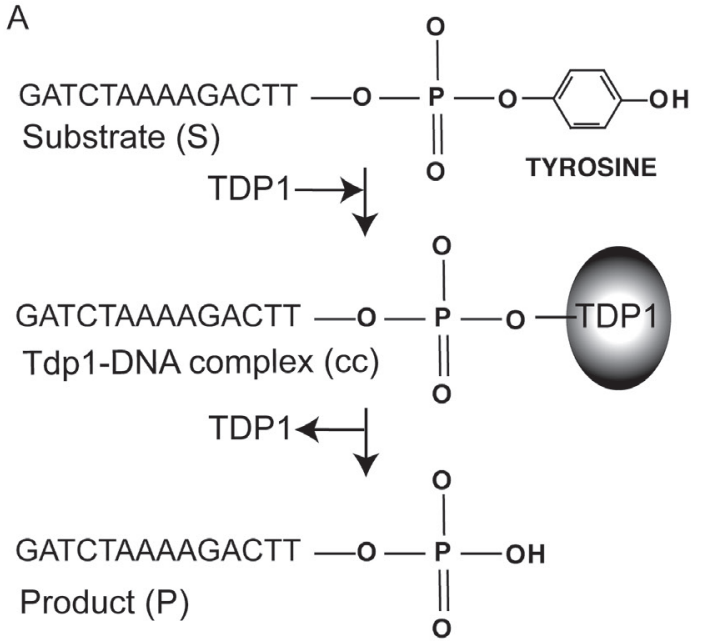

C

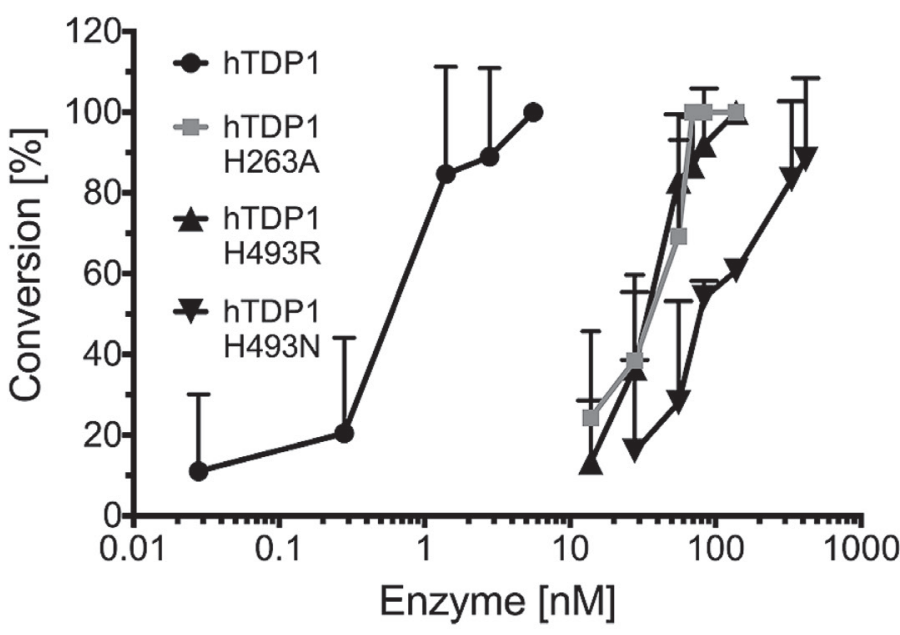

D
B

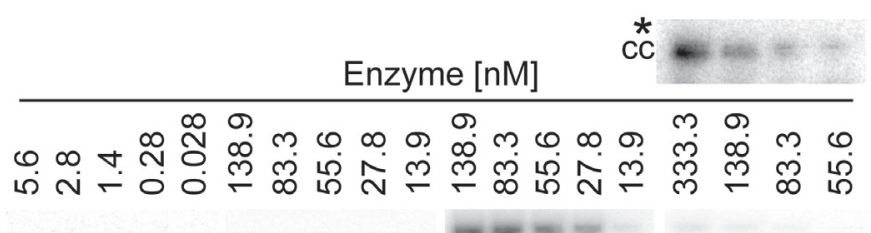

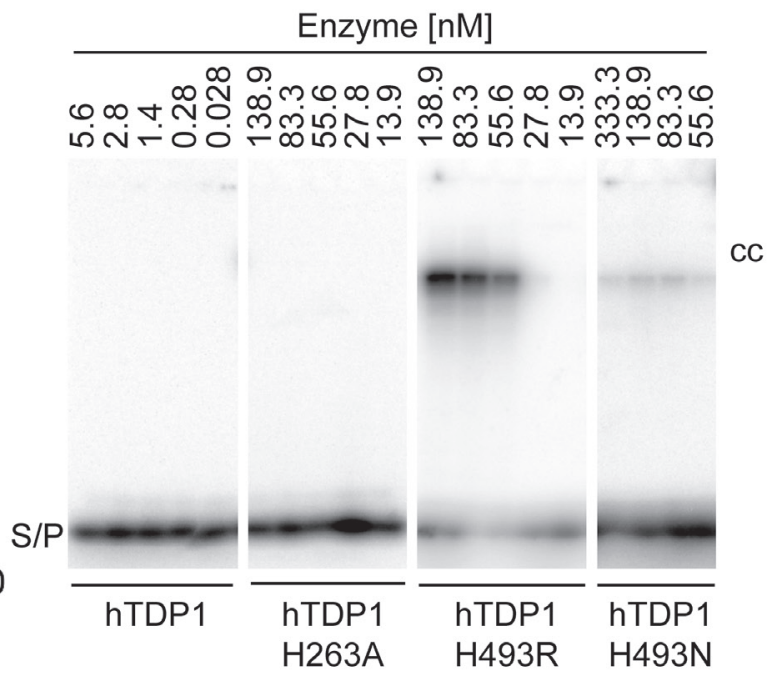

Figure 5: In vitro analysis of catalytic activity of hTDP1 enzymes. A. Schematic of in vitro TDP1 catalytic activity assay. 5'-32 P labeled 14-mer oligonucleotide substrate containing 3'phospho-tyrosine (Substrate (S)) is covalently bound by TDP1 (TDP1-DNA complex (cc)), and subsequently released as 3'phosphoryl end (Product (P)). N-terminally FLAG-tagged hTDP1 protein ranging from 5.6 to 333.3 $\mathrm{nM}$ was incubated with $16.7 \mathrm{nM}$ of $5^{\prime}-^{32} \mathrm{P}$ labeled substrate for 10 minutes at $30^{\circ} \mathrm{C}$. Reactions were split into two aliquots. B. One aliquot was resolved on a denaturing $20 \%$ polyacrylamide/8M urea gel, to detect the conversion of the 3'phospho-tyrosine (S) to 3'phosphoryl (P). Stable covalent enzyme-DNA complexes (cc) migrated into gel just under the well. cc* To detect hTDP1H ${ }^{493} \mathrm{~N}-\mathrm{DNA}$ cc we increased the exposure time from 1 hour to overnight. C. The average and standard deviation of substrate to product conversion (product/[product + substrate]) from (B) were quantitated by ImageStudio Lite (version 3.1.4, LI-COR) of at least three independent experiments. D. The other aliquot was resolved by $12 \%$ SDS-PAGE to detect covalent enzyme-DNA intermediates (cc). Shown are equal exposure times. 
formation by $\sim 30 \%$ (unpaired student t-test; $p=0.0074$ ), while $\mathrm{hTdp} 1 \mathrm{H}^{493} \mathrm{~N}$ showed a significant reduction of $\sim 45 \%$ ( $\mathrm{p}=0.0001$ ), compared to vector control (Figure 8). These results suggest that the $h T d p 1 H^{493} \mathrm{~N}$ mutant is more efficient to prevent anchorage-independent colony formation than the $\mathrm{hTdp} 1 \mathrm{H}^{263} \mathrm{~A}$ mutant, which is a reverse outcome compared to the anchorage-dependent colony formation assay (compare Figure 3A with Figure 8). In summary, these results support the potential of targeting TDP1-cc as a novel anti-cancer treatment strategy, which will act synergistically with chemotherapeutics that induce DNA adducts that function as TDP1 substrates.

\section{DISCUSSION}

Our reported yeast observations suggested that TDP1 is a suitable target to turn a DNA repair enzyme into a cellular toxin as a potential novel anti-cancer treatment strategy $[3,4,32]$. TDP1 is unique among DNA repair enzymes due to the requisite formation of a covalent TDP1-DNA reaction intermediate (Figure 1). Other enzymes that remove adducts from the 3 '- and 5'-end of DNA nicks do not form a covalent enzyme-DNA complex.
For example, TDP2 (also known as TTRAP or EAPII), a multifunctional enzyme that constitutes complementary DNA repair activities with TDP1, hydrolyzing specifically the 5 'phospho-tyrosyl linkage. However, TDP2 utilizes a single- $\mathrm{Mg}^{2+}$-dependent catalysis, a mechanism that is distinct from TDP1, and lacks the formation of covalent enzyme-DNA intermediates [18, 35-37].

Targeting covalent enzyme-DNA intermediates have been proven to be a very effective anti-cancer strategy. For example, etoposide and TPT specifically stabilize the TOPO2-DNA and TOPO1-DNA covalent intermediates, respectively, to induce cytotoxic DNA lesions [12, 13]. The suitability of the TDP1-DNA complex for molecular targeting to develop novel chemotherapeutics is best illustrated by the identification of an hTdp1His ${ }^{\text {gab }} \mathrm{Arg}$ mutant in patients with the autosomal recessive neurodegenerative disease SCAN1 [28]. This mutant enzyme exhibits a reduced dissociation rate resulting in a more stable $\mathrm{hTdp} 1 \mathrm{H}^{493} \mathrm{R}$-DNA intermediate and acts as a mild cellular toxin [3, 28, 29]. Surprisingly, this alteration only causes a progressive cerebellar atrophy whose symptoms first present during the second decade of life without developing other disorders including immuno-deficiencies, cancers,
A
H. sapiens
aa
H $\mathrm{K}$
S. cerevisiae
251 QAKLDIA-FGT HHTKMMLLLYEEG-LRVVIHTSN
P. troglodytes
170 LIEITMPPFAS HHTKLI INFYDNGECKIFLPSNN
M. musculus
321 QAKLDIA-FGTHHTKMMLLLYEEG-LRVVIHTSN
$R$. norvegicus
253 QAKLDIA-FGT HHTKMMLLLYEEG-LRVVIHTSN
C. familiaris
253 QAKLDIA-FGT HHTKMMLLLYEEG-LRVVIHTSN
G. gallus
253 QAKLDIA-FGT HHTKMMLLLYEEG-LRVVIHTSN
B. Taurus
247 QAKLDIA-FGT HHTKMMLLLYEEG-LRVVIHTSN
D. melanogaster
255 QAKLDIA-FGT HHTKMMLLLYEEG-LRVVIHTSN
D. rerio
237 RVKMPTP-FATSHTKMMFLGYSDGSMRVVISTAN
249 QAKLDIA-FGTHHTKMMLLWYEEEGFRVIILTSN

B

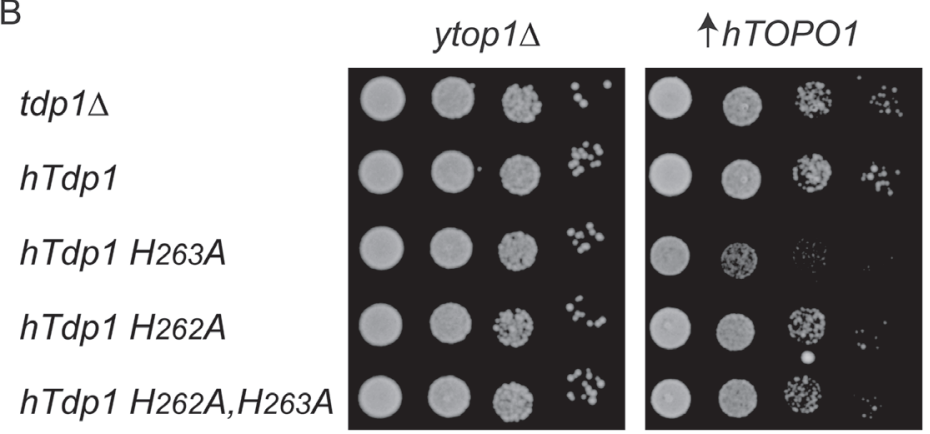

Figure 6: $\mathbf{h T D P} 1 \mathrm{H}^{263} \mathrm{~A}$ toxicity involves the conserved adjacent histidine $\mathbf{H i s}^{262}$. A. Alignment of a selection of TDP1 orthologs first $\mathrm{HxKx}_{(\mathrm{n})} \mathrm{N}$ motif amino acid (aa) sequences. This motif provides the His ${ }^{\text {nuc }}$ (bold) residue; the adjacent His is italicized. UniProt KB/Swiss-Prot protein \#: H sapiens (Q9NUW8), S. cerevisiae (P38319), P. troglodytes (G2HG04), M. musculus (Q8BJ37), R. norvegicus (Q4G056), C. familiars (E2REL5), G. gallus (F1NSQ5), B. Taurus (F1MST1), D. melanogaster (Q9VQM4), D. rerio (E7FEK0). B. top $1 \Delta t d p 1 \triangle$ yeast cells co-transformed with vector control (ytop 1 $\triangle$ ) or $-\mathrm{h} T O P O 1 \cdot \mathrm{U}(\uparrow \mathrm{h} T O P O 1)$ and the indicated YCpGAL1-hTDP1·L or its control vector $(\mathrm{ytdp} 1 \Delta)$. Exponentially growing cells were corrected to an $\mathrm{OD}_{595} 0.3$ and ten-fold serially diluted, spotted onto selective galactose plates, and incubated at $30^{\circ} \mathrm{C}$ for 4 days. 
or myopathy $[28,38]$. The mechanistic defect and mild phenotype of this substitution are conserved from human to yeast [3, 4, 28, 29]]. Moreover, we reported that substituting smaller polar or aliphatic side chains such as Asn for $y \mathrm{Tdp} 1 \mathrm{His}^{\mathrm{gab}}$ results in more severe phenotypes that form stable enzyme-DNA reaction intermediates in the cell but not with an artificial in vitro oligonucleotide substrate [3, 4]. The observations described above, together with our reported yeast model and the pathobiology of the SCAN1 related TDP1 mutant, support the proposed novel treatment strategy of molecular targeting stabilization of the TDP1-DNA covalent complex for cancer treatment. What's more, most TDP1 substrates are formed by clinically active (chemo-)therapeutics and endogenous reactive oxygen species whose levels are elevated in cancer cells $[3,4,11$, $13,14,16-20,22,23,25-27,39-45]$.

Indeed, the herein described observations support that molecular targeting to stabilize the TDP1-DNA intermediate is a potential novel cancer treatment strategy. Expression of human Tdp1 His ${ }^{\text {nuc }}$ Ala and His ${ }^{\text {gab }}$ Asn

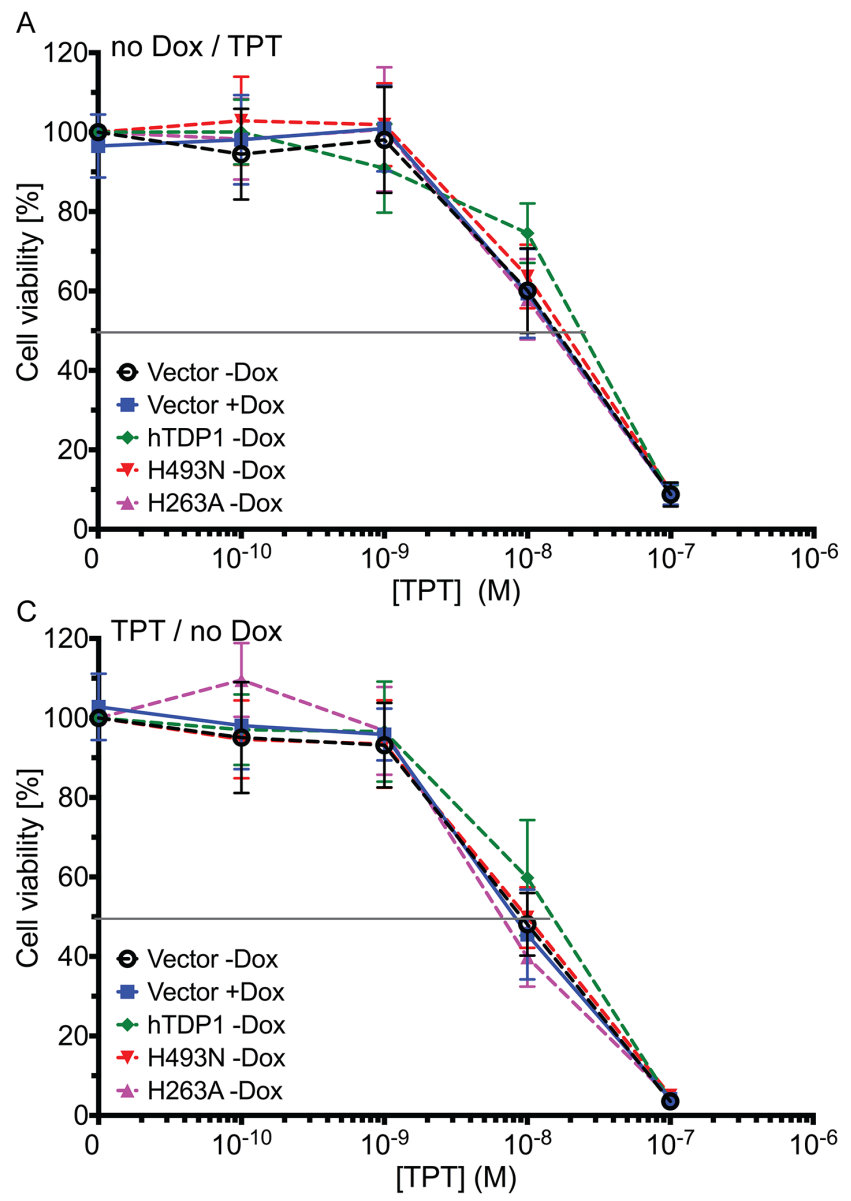

mutants in HEK293 cells show growth inhibition and reduced anchorage-dependent and -independent colony formation compared to wild type (Figure 2A, Figure 7B, 7D and Figure 8). Additionally, these hTDP1 mutants show an accumulation of TDP1-genomic DNA reaction intermediates (Figure 4C). These mutants also display a reduced catalytic activity compared to the wild-type enzyme without an easily detectable formation of enzymeDNA complexes (Figure 5). All these phenotypes are conserved from yeast to human. These results also imply that simple oligonucleotide-based substrates used with in vitro reactions are best suited for determining the catalytic activity of TDP1 in contrast to the formation of covalent intermediates, which are best observed in a cellular based assay. This indicates that covalent intermediates are a product of the sum of more physiologically relevant substrates and protein-protein interactions that are not replicated in vitro.

Yet our observations surprised us on multiple points. First, we detected catalytic activity in vitro and a cellular

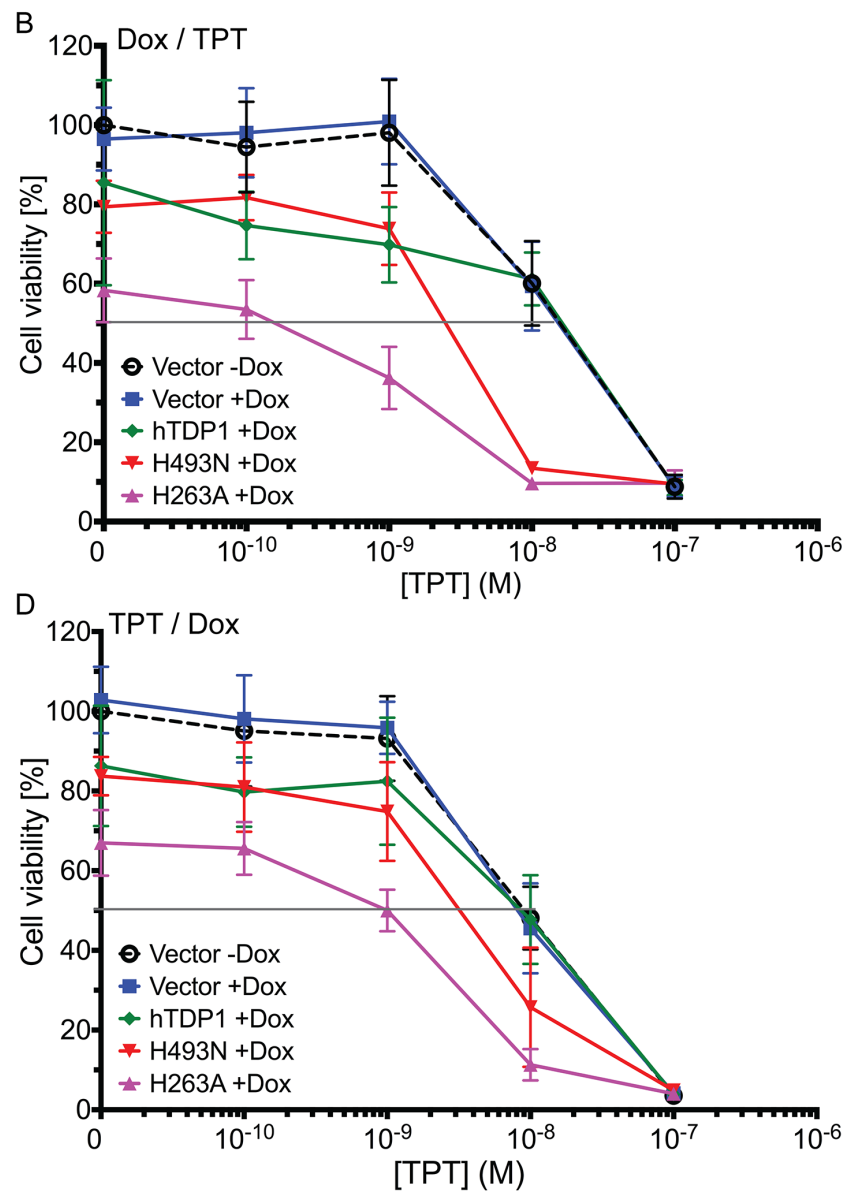

Figure 7: Dysregulated hTDP1 co-treated with topotecan enhances cytotoxicity. Exponentially growing stably transfected HEK293 cells with indicated HAhTDP1 allele or control cells (vector) were seeded 24 hours prior to treatment schedule. A-B. Cells were treated with or without Dox 24 hours prior to topotecan (TPT) treatment of 0.1 to $100 \mathrm{nM}$. C-D. Cells were treated with TPT (0.1 to $100 \mathrm{nM}$ ) 24 hours prior to \pm Dox treatment. 4 days after last treatment cell viability was determined using Allamar blue. Shown is the average and standard deviation of at least 3 independent experiments. A-C. no hTDP1 expression was induced; B-D. hTDP1 expression was induced by $0.1 \mu \mathrm{g} / \mathrm{mL}$ Dox. 
Table 1: $\mathrm{IC}_{50}$ of combination treatment of Tdp1 expression and topotecan

\begin{tabular}{|c|c|c|c|c|c|}
\hline \multicolumn{2}{|c|}{ Schedule $^{@}$} & \multicolumn{2}{|c|}{ TDP1-TPT } & \multicolumn{2}{|c|}{ TPT-TDP1 } \\
\hline Cell line & Dox $\$$ & $\mathrm{IC}_{50}{ }^{\#}$ & Fold Change* & $\mathrm{IC}_{50}{ }^{\#}$ & Fold Change* \\
\hline \multirow[t]{2}{*}{ Vector } & - & 11.0 & & 9.5 & \\
\hline & + & 10.6 & 1.0 & 8.8 & 1.1 \\
\hline \multirow[t]{2}{*}{ hTdp1 } & - & 32.8 & & 13.2 & \\
\hline & + & 18.7 & 1.8 & 9.4 & 1.4 \\
\hline \multirow[t]{2}{*}{$\mathrm{H} 493 \mathrm{~N}$} & - & 11.6 & & 10.0 & \\
\hline & + & 2.5 & 4.6 & 3.9 & 2.6 \\
\hline \multirow[t]{2}{*}{$\mathrm{H} 263 \mathrm{~A}$} & - & 10.6 & & 7.4 & \\
\hline & + & 0.3 & 35.2 & 1.0 & 7.4 \\
\hline
\end{tabular}

@ Schedule TDP1-TPT: 4 days with (+Dox) or without (-Dox) TDP1 expression combined with 3 days TPT; TPT-TDP1. Schedule TPT-TDP1: 4 days TPT combined with 3 days with (+Dox) or without (-Dox) TDP1 expression; $\$-/+0.1 \mu \mathrm{g} / \mathrm{ml}$ to induce Tdp1 allele expression; \# $\mathrm{IC}_{50}$ in $\mathrm{nM}$ calculated from the average survival curve (Figure 7) using Prism 7; * Fold change $=\mathrm{IC}_{50}-\mathrm{Dox} / \mathrm{IC}_{50}+$ Dox, indicate fold increase in cell toxicity in combination with indicated TDP1 protein expression and topotecan (TPT).

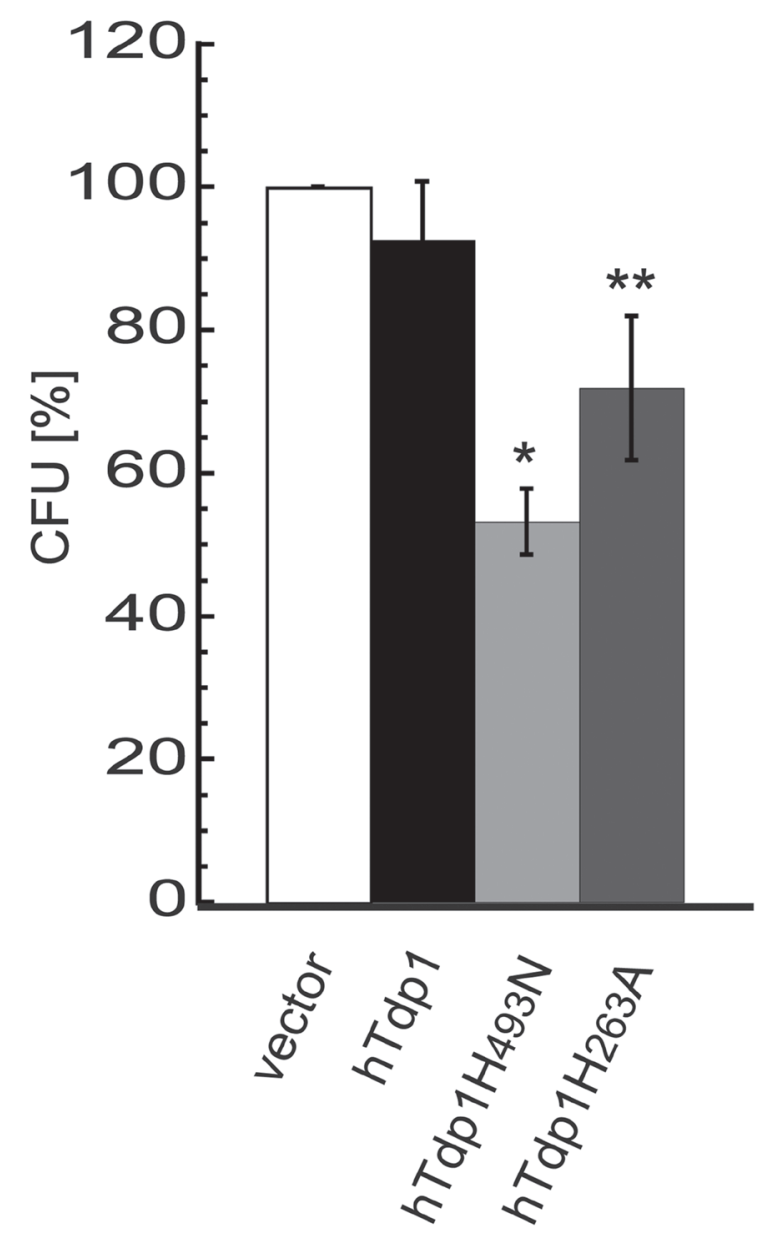

Figure 8: Expression of dysregulated hTDP1 reduces anchorage independent colony formation. Stably transfected HEK293 cells with indicated HAhTDP1 allele were mixed with $0.7 \%$ soft-agar medium \pm Dox, seeded in 6 -well plates and incubated for 21 days. Plates were stained with MTT and colonies were counted. The relative colony forming units (CFU) were determined versus control cell growth (vector). Vector-hTDP1: not significant; Vector-hTdp1 ${ }^{\text {mutant: }}{ }^{*} \mathrm{p}=0.0001 ;{ }^{*} \mathrm{p}=0.0074,(\mathrm{n}=3)$. 
phenotype with the reported catalytic inactive hTdp $1 \mathrm{H}^{263} \mathrm{~A}$ mutant $[5,8]$. We recently reported a similar observation for the analogous yeast yTdp $1 \mathrm{H}^{182} \mathrm{~A}$ mutant [32]. We concluded that the His preceding the His ${ }^{\text {nuc }}$ is able to rotate into the catalytic pocket in case $\mathrm{His}^{\text {nuc }}$ is substituted for Ala [3]. Our results suggest that this action is conserved from yeast to human. An hTdp $1 \mathrm{H}^{262} \mathrm{AH}^{263} \mathrm{~A}$ double mutant did not reduce cell viability in our yeast model (Figure 6B), which was also observed in an anchorage-independent colony formation assay (data not shown, $\mathrm{n}=2$ ). Moreover, this suggests that a catalytic inhibitor of TDP1 might not have a significant biological effect in malignancies in which TDP1 is not essential.

For the second point: Although the exact mechanism underlying the toxicity induced by these Tdp 1 mutants has yet to be determined (ongoing investigation), it involves the formation of more stable TDP1-DNA reaction intermediates (Figure 4). However, the kinetics of these enzyme-DNA covalent complexes is understudied, which is technically challenging to study in cells. Nevertheless, it is interesting that for the most toxic mutant $\left(\mathrm{hTdp} 1 \mathrm{H}^{263} \mathrm{~A}\right)$ we detect smaller amount of enzyme-DNA intermediates than for the lesser toxic hTdp1 $\mathrm{H}^{493} \mathrm{~N}$ mutant (Figure 4C). In general enzyme-DNA intermediates are considered similar in stability, yet the above described data together with our previous observations with yeast Rad9 DNA repair checkpoint deficient strain [32] suggests differently. These catalytic mutants do contain differences as a result of their specific substitutions. Their catalytic pockets are different in electrostatic surface charge and topology (depth, shallowness) as shown for the yeast TDP1 enzymes [3]. This will influence the interaction with the DNA and the conformation of their enzyme-DNA covalent complex, and thus the stability of the complex that correlates with the ability to induce cell lethality.
Thirdly, the observed phenotype of $h T d p 1 \mathrm{H}^{263} \mathrm{~A}$ and hTdp $1 \mathrm{H}^{493} \mathrm{~N}$ in the human cell model without additional genotoxic stress was unexpected. Under similar conditions in our yeast model we do not observe toxicity $[3,4]$. Moreover, TDP1 activity and as such the level of TDP1induced toxicity depends on the existences of TDP1 substrates (DNA adducts) since TDP1 cannot function as an endonuclease [3, 27, 45]. In addition, HEK293 cells express endogenous wild type TDP1, which is able to remove TDP1-DNA intermediates. We hypothesize that this heightened sensitivity observed in human cells compared to yeast is likely due to specific differences between the models. Our yeast model is proficient in all DNA repair and DNA damage response pathways, which is not the case for the human cell model. HEK293 cells and other non-cancerous cell lines are immortalized, while cancer cells contain defects that allow them to continuously grow. HEK293 cells are generated by transfection of sheared adenovirus 5 DNA cells, which resulted in p53 inhibition by the large E1B-proteins of adenovirus 5 [46]. Atsumi et al. recently reported that transformed / immortalized cells that harbor mutant or inhibited ARF or $\mathrm{p} 53$ are more sensitive to DNA damage induced via replication stress, such as treatment with CPT or hydroxyurea, but not other DNA damage, e.g. doxorubicin or cisplatin $[47,48]$. This suggests that the TDP1-induced toxic DNA lesion may result in replication stress to induce the observed cytotoxicity. This suggests that increased stabilization of the covalent TDP1-DNA complex will have a more toxic effect in cells impaired for ARFs/p53 and/or DNA damage response pathway such as cancer cells than in healthy cells. Thus, in contrast to inhibiting TDP1 activity, stabilization of the TDP1DNA reaction intermediate might be a more efficacious therapeutic approach to treat cancer (Figure 9).

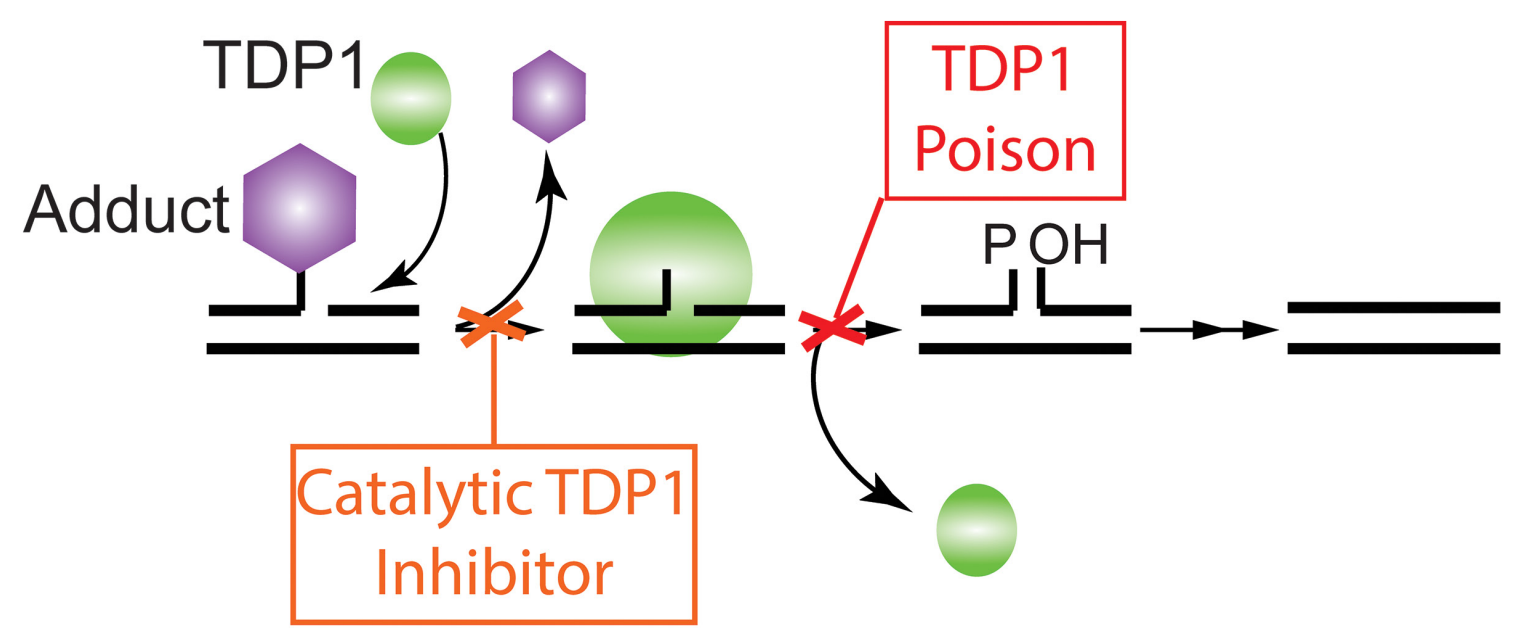

Figure 9: Model of two distinct TDP1 targeted therapeutic approaches. Depicted is a schematic representation of TDP1 twostep catalytic cycle. The first approach; Catalytic TDP1 inhibitor: This approach prevents repair of chemotherapeutics-induced DNA damage, enhancing their efficacy. The second approach; Poisoning or drug-mediated stabilization of the TDP1-DNA covalent complex. This approach represents the ability of molecular stabilization of the obligatory TDP1-DNA reaction intermediate by blocking TDP1 dissociation from the genomic DNA, inducing a more stable DNA-adduct resulting in cell lethality. 


\section{MATERIALS AND METHODS}

\section{Yeast strains and plasmids}

Saccharomyces cerevisiae strain KWY4

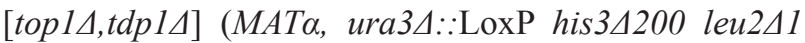
trp1 163 tdp1 $1 \mathrm{SD}$ top $1 \Delta: \because H I S 5)$ was generated from

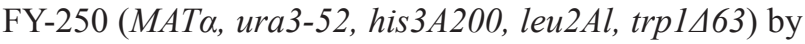
gene replacement of TOP1 with HIS5 and the ura3-52 allele with LoxP- $K A N^{\mathrm{r}}$-LoxP, followed by CRE-mediated recombination to yield ura3 $\because:$ LoxP, and TDP1 using URA3 flanked by gene endogenous TDP1 3'UTR repeats, followed by selection on 5-FOA resulting in tdp1 $\triangle \mathrm{SD}$ (Seamless Delete) to recover URA3-selection [3, 4951]. ECY2 (KWY4, pep $4 \Delta \because: T R P 1$, prb1 $\triangle \because U R A 3)$ was generated by gene replacement of PEP4 with TRP1 and $P R B 1$ with $U R A 3$ in KWY4. In all cases, gene deletions were confirmed by PCR and DNA sequencing.

For yeast cell viability studies, hTDPl is expressed from the galactose-inducible promoter GAL1 in YCpGAL1-hTDP1 L vectors as described in Gajewski et al. [3]. hTDP1 mutant alleles were created using the QuikChangeII Site-Directed Mutagenesis kit (Stratagene). hTOPO1 was expressed from the galactose-inducible GAL1 promoter of the YCpGAL-

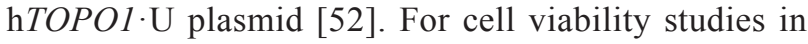
human cells, the $h T D P 1$ alleles were N-terminally HA-tagged via PCR and cloned into the pcDNA4/TO expression vector (pcDNA4/TO-HAhTDP1) containing a tetracycline/doxycycline-inducible $\mathrm{CMVTetO}_{2}$ promoter (Invitrogen).

For protein purification from yeast (see also [32]), N-terminal Flag-tagged hTDP1 constructs, produced by PCR amplification, were subsequently cloned into a YEpGAL4-10GAL1 vector to yield YEpGAL410GAL1-FLAGhTDP1 $\cdot$ L vectors. All $h T D P 1$ alleles were confirmed by DNA sequencing and PCR primer sequences are available upon request.

\section{Immunoblotting of yeast cell extracts}

As described in He et al. [4], exponentially growing cultures of cells transformed with expressing TDP1 under the GAL1 promoter were induced for 6 hours with $2 \%$ galactose, corrected to the same $\mathrm{OD}_{595}$, and lysed with acid-washed glass beads (Sigma) at $4^{\circ} \mathrm{C}$ in $50 \mathrm{mM}$ Tris, pH 8.0, 2 mM EDTA, 2 mM EGTA, 10\% glycerol, and Complete EDTA-free Protease Inhibitor (Roche). Lysate was boiled in SDS buffer for 10 minutes and aliquots were resolved on a $12 \%$ SDS-PAGE, blotted onto PVDF, immunostained with anti-hTDP1 (ab4166, Abcam) and anti-atubulin (MCA77G, AbD Serotec) antibodies, and visualized by chemiluminescence.

All chemiluminescence (in this manuscript) is detected via film or with the ChemiDoc MP Imaging system and Image Lab 5.2.1 software (Bio-Rad). The film was scanned (CanoScan LiDe 200, Canon), and all images (film scans or ChemiDoc acquired) were processed via Adobe Photoshop CS6 to correct signal levels (if needed) of the complete image before cropping the shown area (band of interest $+/-0.5$ to $1 \mathrm{~cm}$ margin). Final figures were generated in Illustrator CS6.

\section{Yeast viability assays}

Semi-quantitative colony formation assays were performed as described in He et al. [4]. Briefly, cultures of yeast cells co-transformed with indicated vectors were diluted to $\mathrm{OD}_{595}$ of 0.3 in TE buffer ( $50 \mathrm{mM}$ Tris, $5 \mathrm{mM}$ EDTA) and 10-fold serial diluted. $5 \mu \mathrm{l}$ aliquots of each dilution were spotted onto selective medium plates containing $2 \%$ galactose and incubated for 4 days at $30^{\circ} \mathrm{C}$. At least three independent experiments were assayed.

\section{HEK293T-REx stably transfected cell lines}

HEK293T-REx cells (Invitrogen) were transfected with Xho1 linearized pcDNA4-CMV-vectors containing the N-terminally HA-tagged hTDPl ORF of interest (wild type hTDP1 or hTDP1 catalytic mutants) or an empty vector as control, using Lipofectamine 2000 in 6-well plates and incubated overnight at $37^{\circ} \mathrm{C}$ and $5 \% \mathrm{CO}_{2}$. Cells were harvested, diluted 1:10, 1:100, $1: 1000$, and seeded in duplicate in $10 \mathrm{~cm}$ dishes for each dilution and incubated at $37^{\circ} \mathrm{C}$ overnight. 24 hours later selection medium DMEM ${ }^{\mathrm{zb}}$ (DMEM supplemented with $10 \%$ FBS, $2 \mathrm{mM}$ L-glutamine, $150 \mu \mathrm{g} / \mathrm{ml}$ zeocin (for pcDNA4 vector) and $5 \mu \mathrm{g} / \mathrm{ml}$ blasticidin [T-REx selection]) was added. The selection medium was replaced every 3-4 days without disturbing the cells. Once colonies were formed, colonies were picked using a collection ring and transferred to a 96-well plate. At 90-95\% confluence cells were transferred to larger wells until steadily grown in T-75 flasks. Multiple clones were isolated for each introduced hTDP1 allele and checked for similar HAhTDP1 protein expression. Multiple clones showed similar expression levels, and two arbitrary series of stably transfected clones were selected. One series was used for all assays in triplicate. The other series was used as a control to omit clonal effects due to the integration of the introduced ectopic plasmid. We observed similar outcomes in all tested assays (data not shown). For all used cell lines, the inserted TDP1 cDNAs of the stably transfected lines were verified via sequencing. In addition, all cell lines were authenticated (June 2016) by the UAB Heflin Center Genomic Core Laboratories using the Applied Biosystems AmpFISTR system to screen 15 different small tandem repeat (STR) markers and the Amelogenin locus for gender determination. These STR markers include those genotyped by the ATCC. 


\section{Anchorage-dependent colony formation assays}

Exponentially growing stably transfected HEK293 cells with indicated HAhTDPI allele or vector control cells were harvested, and 1,000 cells/well in a 6-well plate were seeded in $\mathrm{DMEM}^{\mathrm{zb}}$. After 24 hours, cells in 2 wells were treated with $0.1 \mu \mathrm{g} / \mathrm{ml}$ doxycycline (Dox) to induce $\mathrm{hTDP} 1$ expression, and cells in 2 other wells were not induced. After incubating for 10 days, cells were fixed with $3.7 \%$ paraformaldehyde and stained with $0.025 \%$ crystal violet and air-dried. Colonies were quantified using LI-COR Odyssey Infrared Imager at a fluorescence of $700 \mathrm{~nm}$. The readout (light units or LU) of the 2 wells was averaged for each condition and cell line. The relative cell viability was calculated [LU +Dox/ LU -Dox] x 100\% for each cell line and the average with the standard deviation was determined from at least three independent experiment and plotted. Significance was determined using the unpaired student t-test (Prism 7, GraphPad).

\section{Immunoblotting of fractionated human cell extracts}

Exponentially growing stably transfected HEK293 cells with indicated HAhTDP1 allele or vector control cells were induced with $1 \mu \mathrm{g} / \mathrm{ml}$ Dox in $\mathrm{DMEM}^{\mathrm{bb}}$ for 48 hours. Cells were harvested and equal amounts of cells were resuspended in CLB buffer (10 mM HEPES, $\mathrm{pH}$ $8.0,10 \mathrm{mM} \mathrm{NaCl}, 1 \mathrm{mM} \mathrm{KH}_{2} \mathrm{PO}_{4}, 5 \mathrm{mM} \mathrm{NaHCO}, 1 \mathrm{mM}$ $\mathrm{CaCl}_{2}, 0.5 \mathrm{mM} \mathrm{MgCl}$ ). The lysate was centrifuged at $5000 \mathrm{~g}$ at $4^{\circ} \mathrm{C}$ for 5 minutes and cytosolic/mitochondrial fraction (supernatant) was collected. To obtain genomic DNA fraction, the (nuclear) pellet was resuspended in TSE buffer (10 mM Tris, pH 7.5, $300 \mathrm{mM}$ sucrose, $1 \mathrm{mM}$ EDTA), incubated for 30 minutes on ice, and centrifuged at $2300 \mathrm{~g}$ at $4^{\circ} \mathrm{C}$ for 5 minutes. The nucleoplasm (supernatant) was collected and the pellet washed twice with TSE buffer and sonicated to shear the genomic DNA to re-solubilize covalently bound proteins. All buffers contain Complete EDTA-free protease inhibitor (Roche). Lysate aliquots were resolved on a $12 \%$ SDS-PAGE, blotted onto PVDF and immunostained with anti-hTDP1 and anti-atubulin or anti-Histone H3 (Ab46765, Abcam) antibodies, and visualized by chemiluminescence. Images are processed as described in "immunoblotting of yeast extracts."

\section{Band-depletion of TDP1 protein}

Exponentially growing stably transfected HEK293 cells with indicated HAhTDP1 allele or vector control cells were induced with $1 \mu \mathrm{g} / \mathrm{ml}$ Dox in $\mathrm{DMEM}^{\mathrm{zb}}$ for 48 hours. Cells were harvested and equal amounts of cells were resuspended in lysis buffer $(200 \mathrm{mM} \mathrm{NaOH}$, 5 mM EDTA), incubated for 15 minutes on ice and then neutralized with Neutralization buffer $(600 \mathrm{mM}$ Tris, $\mathrm{pH}$
8.0). Half of the cell lysate was added to $6 \mathrm{X}$ SDS sample buffer and boiled, while to the other half 6,000 gel units of Micrococcal Nuclease (NEB) was added and incubated at $37^{\circ} \mathrm{C}$ for 30 minutes. Digestion of genomic DNA was stopped by addition of 6X SDS sample buffer and boiling. Aliquots were resolved on a $12 \%$ SDS-PAGE, blotted onto PVDF and immunostained with anti-hTDP1 and antiatubulin antibodies, and visualized by chemiluminescence. Images are processed as described in "immunoblotting of yeast extracts."

\section{Purification of hTDP1 protein from yeast extracts}

N-terminal Flag-tagged hTDP1 alleles were expressed from YEpGal4-10GAL1-FLAGhTDP1-L vectors in protease-deficient top $14, t d p 1 \Delta$ cells (ECY2 strain). Exponential cultures were induced with $2 \%$ galactose for 6 hours, cells were harvested, and FLAGhTDP1 protein purified as described in [32]. Briefly, cell extracts in HEE/2PI buffer (50 mM HEPES, $\mathrm{pH} 8.0$, $5 \mathrm{mM}$ EDTA, 5mM EGTA, 2PI [2xprotease inhibitor cocktail, Sigma]) were loaded onto SP Sepharose fast flow matrix (GE Life Sciences) and eluted with HEE/2PI/0.4 $\mathrm{M} \mathrm{NaCl}$, then affinity purified by anti-FLAG M2 affinity chromatography matrix (Sigma). FLAGhTDP1 was eluted with $3 X$ FLAG peptide in TEEK (50 mM Tris, $\mathrm{pH} 7.5,1$ mM EDTA, 1 mM EGTA, $100 \mathrm{mM} \mathrm{KCl}, 1 \mathrm{mM}$ DTT) and concentrated in an Ultracel-30K concentrator (Millipore). Concentration was determined by Bradford-assay (Bio Rad) and purity was determined by sypro-ruby (Bio Rad) staining of hTDP1 fractions resolved by $12 \%$ SDS-PAGE.

\section{hTDP1 in vitro activity assay}

Activity assays were performed as described in Gajewski et al. [3]. Briefly, 14-mer (5'-GATCTAAAAGACTT-3') oligonucleotide with a 3'phospho-tyrosine was used as a substrate and an identical oligonucleotide with a 3'-phosphate was used as product control (Midland Certified Reagent Company, Inc.). $5{ }^{3}{ }^{32} \mathrm{P}$ end-labeled oligonucleotides $(250 \mathrm{fmol})$ were incubated in $18 \mu$ reaction buffer $(50 \mathrm{mM}$ Tris, $\mathrm{pH} 7.5$, $1 \mathrm{mM}$ EDTA, $100 \mathrm{mM} \mathrm{KCl}, 2 \mathrm{mM}$ DTT) with indicated amounts of TDP1 for $10 \mathrm{~min}$ at $30^{\circ} \mathrm{C}$. Reaction samples were split and either combined with USB stop buffer/ $8 \mathrm{M}$ Urea for analysis in $20 \% \mathrm{PAA} / \mathrm{Urea}$ sequencing gel or with 6xSDS-PAGE sample buffer for analysis in $12 \%$ SDS-PAGE. Reaction products were visualized by Phosphor-Imager screens, scanned with a Storm 865 scanner (GE Life Sciences), and quantified with Image Studio Software version 3.1.4 LI-COR). All images were processed in Adobe Photoshop CS6 to correct signal levels of the complete image followed by cropping one enzyme's concentration range to obtain separated panels, and final figures were generated in Illustrator CS6. 


\section{Cell viability assay}

Exponentially growing stably transfected HEK293 cells with indicated HAhTDPI allele or vector control cells were seeded at 2000 cells/well in 96-well plates. The following day cells were treated with or without 0.1 $\mu \mathrm{g} / \mathrm{ml}$ Dox in $\mathrm{DMEM}^{2 \mathrm{~b}}$ and 24 hours later with various concentrations ranging from $1-100 \mathrm{ng} / \mathrm{ml}$ of topotecan (TPT) or vice versa depending on the treatment schedule (+/- Dox [to induce hTDP1 expression] followed by TPT or TPT followed by +/-Dox). After 4 days of incubation, cells were treated with $10 \%$ (v/v) AlamarBlue (Invitrogen) and incubated at $37^{\circ} \mathrm{C}$ for 2 hours. Plates were read on the SpectraMax M5 plate reader (Molecular Devices) at a fluorescence of 530/590 nm. Relative cell viability was determined relative to DMSO (vertical) treatment. Four wells were used per condition in each experiment and the average and standard deviation of at least three independent experiments were plotted and analyzed using Prism 7 (GraphPad).

\section{Anchorage-independent-colony formation assays}

Exponentially growing stably transfected HEK293 cells with indicated HAhTDP1 allele or vector control cells were harvested, and 30,000 cells were mixed with $\mathrm{DMEM}^{\mathrm{zb}} / 0.7 \%$ agarose, with or without $1 \mu \mathrm{g} / \mathrm{ml}$ Dox, and plated onto $\mathrm{DMEM}^{\mathrm{zb}} / 2 \%$ agarose with or without $1 \mu \mathrm{g} / \mathrm{ml}$ Dox in 6-well plates and incubated for 21 days, then stained with MTT (5 mg/ml in PBS) overnight and colonies counted. Each cell line and condition (+/- Dox) was seeded in duplicate. The relative colony forming units (CFU) were determined versus vector control for each condition (with or without Dox induction). Plotted is the average and standard deviation of three independent experiments for each condition. The no Dox results showed no significant difference versus vector control (data not shown). Significance was determined using the unpaired student t-test.

\section{ACKNOWLEDGMENTS}

We would like to thank Dr. Shih-Hsin (Eddy) Yang for critical reading and discussions, Ms. Kellie Regal and Mr. Evan Brettrager for technical assistance, and Ms. Lisa Park for editorial assistance.

\section{CONFLICTS OF INTEREST} interest

The authors declare that they have no conflicts of

\section{GRANT SUPPORT}

RCAMvW greatly appreciates the financial support from the Department of Pharmacology and Toxicology, the
Alabama Drug Discovery Alliance, UAB ACS-IRG Junior Faculty Development Grant (ACS-IRG-60-001-53), the UAB CCC Faculty Development Grant (Cancer Center Core Support Grant P30CA013148), and DOD OCRP pilot award W81XWH-15-1-0198.

\section{REFERENCES}

1. Comeaux EQ, van Waardenburg RC. Tyrosyl-DNA phosphodiesterase I resolves both naturally and chemically induced DNA adducts and its potential as a therapeutic target. Drug Metab Rev. 2014; 46:494-507.

2. Davies DR, Interthal H, Champoux JJ, Hol WG. Crystal structure of a transition state mimic for Tdp1 assembled from vanadate, DNA, and a topoisomerase I-derived peptide. Chemistry \& biology. 2003; 10:139-147.

3. Gajewski S, Comeaux EQ, Jafari N, Bharatham N, Bashford D, White SW, van Waardenburg RC. Analysis of the activesite mechanism of tyrosyl-DNA phosphodiesterase I: a member of the phospholipase D superfamily. Journal of molecular biology. 2012; 415:741-758.

4. He X, van Waardenburg RC, Babaoglu K, Price AC, Nitiss KC, Nitiss JL, Bjornsti MA, White SW. Mutation of a conserved active site residue converts tyrosyl-DNA phosphodiesterase I into a DNA topoisomerase I-dependent poison. Journal of molecular biology. 2007; 372:1070-1081.

5. Interthal H, Pouliot JJ, Champoux JJ. The tyrosyl-DNA phosphodiesterase Tdp1 is a member of the phospholipase D superfamily. Proceedings of the National Academy of Sciences of the United States of America. 2001; 98:12009-12014.

6. Pouliot JJ, Robertson CA, Nash HA. Pathways for repair of topoisomerase I covalent complexes in Saccharomyces cerevisiae. Genes to cells : devoted to molecular \& cellular mechanisms. 2001; 6:677-687.

7. Pouliot JJ, Yao KC, Robertson CA, Nash HA. Yeast gene for a Tyr-DNA phosphodiesterase that repairs topoisomerase I complexes. Science. 1999; 286:552-555.

8. Raymond AC, Rideout MC, Staker B, Hjerrild K, Burgin $\mathrm{AB}, \mathrm{Jr}$. Analysis of human tyrosyl-DNA phosphodiesterase I catalytic residues. Journal of molecular biology. 2004; 338:895-906.

9. Champoux JJ. DNA topoisomerases: structure, function, and mechanism. Annual review of biochemistry. 2001; 70:369-413.

10. Pommier Y. Topoisomerase I inhibitors: camptothecins and beyond. Nature reviews Cancer. 2006; 6:789-802.

11. Wang JC. Cellular roles of DNA topoisomerases: a molecular perspective. Nature reviews Molecular cell biology. 2002; 3:430-440.

12. Chen GL, Yang L, Rowe TC, Halligan BD, Tewey KM, Liu LF. Nonintercalative antitumor drugs interfere with the breakage-reunion reaction of mammalian DNA topoisomerase II. The Journal of biological chemistry. 1984; 259:13560-13566. 
13. Hsiang YH, Hertzberg R, Hecht S, Liu LF. Camptothecin induces protein-linked DNA breaks via mammalian DNA topoisomerase I. The Journal of biological chemistry. 1985; 260:14873-14878.

14. Barthelmes HU, Habermeyer M, Christensen MO, Mielke C, Interthal H, Pouliot JJ, Boege F, Marko D. TDP1 overexpression in human cells counteracts DNA damage mediated by topoisomerases I and II. The Journal of biological chemistry. 2004; 279:55618-55625.

15. Borda MA, Palmitelli M, Veron G, Gonzalez-Cid M, de Campos Nebel M. Tyrosyl-DNA-phosphodiesterase I (TDP1) participates in the removal and repair of stabilizedTop2alpha cleavage complexes in human cells. Mutation research. 2015; 781:37-48.

16. Hsiang YH, Lihou MG, Liu LF. Arrest of replication forks by drug-stabilized topoisomerase I-DNA cleavable complexes as a mechanism of cell killing by camptothecin. Cancer research. 1989; 49:5077-5082.

17. Interthal H, Chen HJ, Champoux JJ. Human Tdp1 cleaves a broad spectrum of substrates, including phosphoamide linkages. The Journal of biological chemistry. 2005; 280:36518-36528.

18. Murai J, Huang SY, Das BB, Dexheimer TS, Takeda S, Pommier Y. Tyrosyl-DNA phosphodiesterase 1 (TDP1) repairs DNA damage induced by topoisomerases I and II and base alkylation in vertebrate cells. The Journal of biological chemistry. 2012; 287:12848-12857.

19. Nitiss KC, Malik M, He X, White SW, Nitiss JL. TyrosylDNA phosphodiesterase (Tdp1) participates in the repair of Top2-mediated DNA damage. Proceedings of the National Academy of Sciences of the United States of America. 2006; 103:8953-8958.

20. Schoeffler AJ, Berger JM. DNA topoisomerases: harnessing and constraining energy to govern chromosome topology. Quarterly reviews of biophysics. 2008; 41:41-101.

21. Yang W. Topoisomerases, site-specific recombinases: similarities in structure and mechanism. Critical reviews in biochemistry and molecular biology. 2010; 45:520-534.

22. Huang SY, Murai J, Dalla Rosa I, Dexheimer TS, Naumova A, Gmeiner WH, Pommier Y. TDP1 repairs nuclear and mitochondrial DNA damage induced by chain-terminating anticancer and antiviral nucleoside analogs. Nucleic acids research. 2013; 41:7793-7803.

23. Inamdar KV, Pouliot JJ, Zhou T, Lees-Miller SP, RasouliNia A, Povirk LF. Conversion of phosphoglycolate to phosphate termini on 3 ' overhangs of DNA double strand breaks by the human tyrosyl-DNA phosphodiesterase hTdp1. The Journal of biological chemistry. 2002; 277:27162-27168.

24. Lebedeva NA, Anarbaev RO, Kupryushkin MS, Rechkunova NI, Pyshnyi DV, Stetsenko DA, Lavrik OI. Design of a New Fluorescent OligonucleotideBased Assay for a Highly Specific Real-Time Detection of Apurinic/Apyrimidinic Site Cleavage by
Tyrosyl-DNA Phosphodiesterase 1. Bioconjug Chem. 2015; 26:2046-2053.

25. Lebedeva NA, Rechkunova NI, Ishchenko AA, Saparbaev M, Lavrik OI. The mechanism of human tyrosyl-DNA phosphodiesterase 1 in the cleavage of AP site and its synthetic analogs. DNA repair. 2013; 12:1037-1042.

26. Lebedeva NA, Rechkunova NI, Lavrik OI. AP-site cleavage activity of tyrosyl-DNA phosphodiesterase 1. FEBS letters. 2011; 585:683-686.

27. Raymond AC, Staker BL, Burgin AB, Jr. Substrate specificity of tyrosyl-DNA phosphodiesterase I (Tdp1). The Journal of biological chemistry. 2005; 280:22029-22035.

28. Takashima H, Boerkoel CF, John J, Saifi GM, Salih MA, Armstrong D, Mao Y, Quiocho FA, Roa BB, Nakagawa M, Stockton DW, Lupski JR. Mutation of TDP1, encoding a topoisomerase I-dependent DNA damage repair enzyme, in spinocerebellar ataxia with axonal neuropathy. Nature genetics. 2002; 32:267-272.

29. Interthal H, Chen HJ, Kehl-Fie TE, Zotzmann J, Leppard JB, Champoux JJ. SCAN1 mutant Tdp1 accumulates the enzyme--DNA intermediate and causes camptothecin hypersensitivity. The EMBO journal. 2005; 24:2224-2233.

30. El-Khamisy SF, Saifi GM, Weinfeld M, Johansson F, Helleday T, Lupski JR, Caldecott KW. Defective DNA single-strand break repair in spinocerebellar ataxia with axonal neuropathy-1. Nature. 2005; 434:108-113.

31. Zhou T, Lee JW, Tatavarthi H, Lupski JR, Valerie K, Povirk LF. Deficiency in 3'-phosphoglycolate processing in human cells with a hereditary mutation in tyrosyl-DNA phosphodiesterase (TDP1). Nucleic acids research. 2005; 33:289-297.

32. Comeaux EQ, Cuya SM, Kojima K, Jafari N, Wanzeck KC, Mobley JA, Bjornsti MA, van Waardenburg RC. TyrosylDNA phosphodiesterase I catalytic mutants reveal an alternative nucleophile that can catalyze substrate cleavage. The Journal of biological chemistry. 2015; 290:6203-6214.

33. Mori S, Chang JT, Andrechek ER, Matsumura N, Baba T, Yao G, Kim JW, Gatza M, Murphy S, Nevins JR. Anchorage-independent cell growth signature identifies tumors with metastatic potential. Oncogene. 2009; 28:2796-2805.

34. Sioud M, Forterre P. Ciprofloxacin and etoposide (VP16) produce a similar pattern of DNA cleavage in a plasmid of an archaebacterium. Biochemistry. 1989; 28:3638-3641.

35. Nitiss JL, Nitiss KC. Tdp2: a means to fixing the ends. PLoS genetics. 2013; 9:e1003370.

36. Schellenberg MJ, Appel CD, Adhikari S, Robertson PD, Ramsden DA, Williams RS. Mechanism of repair of 5'-topoisomerase II-DNA adducts by mammalian tyrosylDNA phosphodiesterase 2. Nature structural \& molecular biology. 2012; 19:1363-1371.

37. Zeng Z, Cortes-Ledesma F, El Khamisy SF, Caldecott KW. TDP2/TTRAP is the major 5'-tyrosyl DNA phosphodiesterase activity in vertebrate cells and is 
critical for cellular resistance to topoisomerase II-induced DNA damage. The Journal of biological chemistry. 2011; 286:403-409.

38. Fam HK, Salih MAM, Takashima H, Boerkoel CF. (1993). Spinocerebellar Ataxia with Axonal Neuropathy, Autosomal Recessive. In: Pagon RA, Adam MP, Bird TD, Dolan CR, Fong CT and Stephens K, eds. GeneReviews. (Seattle (WA).

39. Caputo F, Vegliante R, Ghibelli L. Redox modulation of the DNA damage response. Biochemical pharmacology. 2012; 84:1292-1306.

40. Hsiang YH, Liu LF. Identification of mammalian DNA topoisomerase I as an intracellular target of the anticancer drug camptothecin. Cancer research. 1988; 48:1722-1726.

41. Ivanova D, Bakalova R, Lazarova D, Gadjeva V, Zhelev Z. The Impact of Reactive Oxygen Species on Anticancer Therapeutic Strategies. Advances in clinical and experimental medicine. 2013; 22:899-908.

42. Lebedeva NA, Rechkunova NI, El-Khamisy SF, Lavrik OI. Tyrosyl-DNA phosphodiesterase 1 initiates repair of apurinic/apyrimidinic sites. Biochimie. 2012; 94:1749-1753.

43. Nivens MC, Felder T, Galloway AH, Pena MM, Pouliot JJ, Spencer HT. Engineered resistance to camptothecin and antifolates by retroviral coexpression of tyrosyl DNA phosphodiesterase-I and thymidylate synthase. Cancer chemotherapy and pharmacology. 2004; 53:107-115.

44. Pommier Y, Leo E, Zhang H, Marchand C. DNA topoisomerases and their poisoning by anticancer and antibacterial drugs. Chemistry \& biology. 2010; 17:421-433.

45. Yang SW, Burgin AB, Jr., Huizenga BN, Robertson CA, Yao KC, Nash HA. A eukaryotic enzyme that can disjoin dead-end covalent complexes between DNA and type I topoisomerases. Proceedings of the National Academy of Sciences of the United States of America. 1996; 93:11534-11539.

46. Graham FL, van der Eb AJ. A new technique for the assay of infectivity of human adenovirus 5 DNA. Virology. 1973; 52:456-467.

47. Atsumi Y, Fujimori H, Fukuda H, Inase A, Shinohe K, Yoshioka Y, Shikanai M, Ichijima Y, Unno J, Mizutani S, Tsuchiya N, Hippo Y, Nakagama H, Masutani M, Teraoka $\mathrm{H}$, Yoshioka K. Onset of quiescence following p53 mediated down-regulation of H2AX in normal cells. PloS one. 2011; 6:e23432.

48. Atsumi Y, Inase A, Osawa T, Sugihara E, Sakasai R, Fujimori H, Teraoka H, Saya H, Kanno M, Tashiro F, Nakagama H, Masutani M, Yoshioka K. The Arf/p53 protein module, which induces apoptosis, down-regulates histone H2AX to allow normal cells to survive in the presence of anti-cancer drugs. The Journal of biological chemistry. 2013; 288:13269-13277.

49. Akada R, Kitagawa T, Kaneko S, Toyonaga D, Ito S, Kakihara Y, Hoshida H, Morimura S, Kondo A, Kida K. PCR-mediated seamless gene deletion and marker recycling in Saccharomyces cerevisiae. Yeast. 2006; 23:399-405.

50. Kauh EA, Bjornsti MA. SCT1 mutants suppress the camptothecin sensitivity of yeast cells expressing wildtype DNA topoisomerase I. Proceedings of the National Academy of Sciences of the United States of America. 1995; 92:6299-6303.

51. Sauer B, Henderson N. Targeted insertion of exogenous DNA into the eukaryotic genome by the Cre recombinase. The New biologist. 1990; 2:441-449.

52. Bjornsti MA, Benedetti P, Viglianti GA, Wang JC. Expression of human DNA topoisomerase I in yeast cells lacking yeast DNA topoisomerase I: restoration of sensitivity of the cells to the antitumor drug camptothecin. Cancer research. 1989; 49:6318-6323. 